\title{
Software review: Is there a role for Activity Based Costing (ABC) in database marketing?
}

Received: 16th October, 2002

\section{Shaun Doyle}

is Vice-President, Intelligent Marketing Solutions, SAS. In this role he works with various parts of the SAS organisation to develop business-oriented solutions for marketing, particularly the SAS Marketing Automation (MA) Solution.

He was the co-founder and chairman of Intrinsic, a campaign management software vendor acquired by SAS in March, 2001. He has extensive experience in the design, development and implementation of customer-focused database marketing systems in a number of business sectors, and has helped design and build more than 150 marketing databases for blue-chip enterprises in financial services, retail and telecommunications, and other industries as well.

$\mathrm{He}$ is well known in the marketing industry and a regular participant in leading industry conferences. He is also the author of a number of papers on the application of database marketing that have been published in the UK and elsewhere.

Earlier in his career, he co-founded Berry Consulting, a firm specialising in database marketing.

Abstract This paper describes the basic principles of Activity Based Costing (ABC) and explores its potential application in database marketing.

\section{Introduction}

The author has been involved in a number of projects around the world where database marketing teams have been establishing Key Performance Indicators frameworks (KPI) for monitoring the effectiveness of direct marketing activities. These have ranged from simple campaign performance reporting solutions to complex customer orientated balanced scorecards.

One issue that appears to be poorly managed in most cases is the treatment of indirect costs (picked up by other departments) when monitoring the effectiveness of marketing activities.

This paper looks at the basic principles of Activity Based Costing (ABC) and explores its potential application in database marketing.

\section{DEFINITION}

The following is a simple definition of ABC.
Activity-based costing (ABC) provides organisations with a means to measure and improve its processes. $\mathrm{ABC}$ is a technique that identifies the costs of specific activities based on their use of resources. It allows management to compare costs of activities based on process rather than the traditional departmental or functional approach to cost measurement.

$\mathrm{ABC}$ has been popular in the manufacturing sector for many years and its use is well established. But the last few years have seen the use of $\mathrm{ABC}$ spreading to other business functions. Its use in marketing is still very embryonic but this will probably change as marketers start to understand the value that this technique provides.

\section{WHAT ARE THE POTENTIAL APPLICATION AREAS FOR ABC?}

The following are the potential application areas for $\mathrm{ABC}$ in database marketing: 
- customer profitability analysis

- channel profitability analysis

- channel optimisation

- campaign performance analysis

- response management.

\section{WHAT IS ABC?}

ABC was developed as a practical tool to solve a problem faced by most companies today. Traditional cost accounting systems have evolved primarily to serve the function of inventory valuation (satisfying the generally accepted accounting principles (GAAP) standards of 'objectivity, verifiability, and materiality'), for external audiences such as the financial regulatory authorities, Inland Revenue, creditors and investors. These traditional systems have many failings, however, especially when used for internal management purposes. Two especially important failings are their inability to:

- report individual product or process costs to a reasonable level of accuracy

- provide useful feedback to management for the purpose of operational control.

As a result, managers of companies selling multiple products through multiple channels are making important decisions about resource allocation based on inaccurate and inappropriate cost information.

Traditional cost systems focus on the product, function or organisational unit in the costing process. The costs are traced to the product, because each product item is assumed to consume the resources in proportion to the volume produced. Therefore, volume attributes of the product item, such as the number of direct labour hours, machine hours or material dollars, are used as the 'drivers' to allocate overhead costs. These volume drivers, however, fail to account for product diversity in the form of size or complexity. Also, there is not always a direct relationship between production volume and cost consumption.

By contrast, $\mathrm{ABC}$ focuses on activities in the costing process. Costs are traced from activities to products, based on the product's demand for these activities during the production/sales process. Therefore, activity attributes such as hours of set-up time, number of tasks or number of times handled are used as the 'drivers' to allocate overhead costs. As the number of activity measures used increases, $\mathrm{ABC}$ is better able to capture the underlying economics of the business's operation, and the reported product sales and marketing costs or marketing process costs become more accurate.

Examples of marketing process costs include:

- cost of executing a communication by direct mail or e-mail

- cost of managing a response via a call centre or branch

- cost of managing returned direct mail.

These process costs may have very different drivers. For example, the costs of outward bound call may be driven by:

- hit rate (number of calls making contact)

- duration of call

— time of day

— skill requirements for the proposition.

The cost of executing a sale through the branch network may be driven by:

— number of handoffs

- location of branch

— skill set of staff in branch

— complexity of product selected. 
Another important distinction between traditional cost systems and $\mathrm{ABC}$ is the scope of operations. Traditional systems, being concerned primarily with business functions, eg marketing, track only those costs incurred by the function, eg campaign-related spend. ABC theory contends that all the costs incurred by the organisation in managing the end-to-end customer communication process should be taken into account. Examples of these process costs in marketing include:

- campaign planning

- campaign execution

- response management

- campaign monitoring

- campaign analysis.

This means that costs may be picked up from other business functions and not just marketing. Possible sources of cost data include:

— logistics (where appropriate)

- customer service

- general administration

- production

— technology

- distribution

— sales

- financial administration

— information resources.

\section{WHAT GAVE RISE TO ABC?}

Many managers understand intuitively that their accounting systems distort product and process costs, so they make informal adjustments to compensate. Few managers, however, can predict the magnitude and impact of the adjustments they should be making. $\mathrm{ABC}$ was first developed as a solution to these problems by two professors at Harvard, Robin Cooper and Robert Kaplan. They identified three independent but concurrent factors as the prime reasons behind the need for, and the practicality of, $\mathrm{ABC}$ : changes in cost structures; increased competition; and availability of technology.

Changes in cost structures: The cost structure process has changed dramatically. At the beginning of the 20 th century, direct labour accounted for about 50 per cent of total product costs, with material being 35 per cent and overhead 15 per cent. Now, overheads typically comprise about 60 per cent of product costs, with material being 30 per cent and direct labour less than 10 per cent. Obviously, using direct labour hours as the allocation basis made sense 90 years ago, but it has no validity at all given today's cost structure.

Increased competition: The level of competition that most organisations face has increased dramatically. Knowledge of real product or process costs is key to surviving in this new competitive situation.

Availability of technology: The cost of measurement has fallen as information processing technology has improved. Even 20 years ago, it would have been cost prohibitive to accumulate, process and analyse the data necessary to run an ABC system. Today, however, such activity measurement systems are not only affordable, but many of the data already exist in some form within the organisation. Therefore, $\mathrm{ABC}$ can be extremely valuable to an organisation, because it provides information on the range, cost and consumption of operating activities.

\section{WHAT ARE THE BENEFITS OF ABC?}

The following are some of the specific benefits of $A B C$ and potential strategic uses of this type of information.

The first is that more accurate product 
or process costs enable better strategic decisions regarding:

- product pricing

- product mix

- process design

- process automation

- channel organisation and strategies

- marketing spend

— investments in R\&D.

Secondly, increased visibility of the activities performed (because ABC maps the activities and traces costs to them) enables a company to:

- focus more on the management of activities, such as improving the efficiency of high-cost activities

- identify and reduce non-value-added activities.

\section{WHAT ARE THE TYPICAL STAGES IN AN ABC PROJECT?}

There are a large number of well-documented ABC methodologies. ${ }^{1}$ As a general rule they follow the key steps below.

\section{Project initiation}

This stage of the project is concerned with determining:

- objectives of the project

- scope of the study

- project team members

— project plan listing key tasks and timescales

- deliverables

— assumptions.

This information would normally be documented in the project terms of reference or project definition document.

Example scope: cost of using call centre for outward-bound calls.

\section{Process documentation}

This stage of the project is concerned with:

- defining the key processes

- defining the relationship between the key processes

- identifying parties implicated in the process execution

- roles of parties in the processes

— input to the processes

- output from the processes

— process descriptions.

This information would be documented as a process map and associated descriptions.

Example processes: set up campaign, set up script, brief telemarketing team, execute calls, monitor call performance.

\section{Activities breakdown}

Where a process is complex it may be necessary to decompose it into the individual activities, these may be system or people supported.

- defining the component activities for the key processes

- defining the relationship between the various activities with a process

- identifying parties implicated in the activity execution

- roles of parties in the activity

- input to the activity

- output from the activity

- activity descriptions.

This information would be documented as an activity map and associated descriptions.

Example activity: set up campaign (process), produce campaign business case, produce supplier brief, manage supplier responses, enter campaign reference data in campaign management tool, select target audience for campaign, 
set up campaign performance reports (Activities).

The key for $\mathrm{ABC}$ is to break down the processes to the right level, too detailed and the marketer ends up with too much data.

\section{Determination of cost driver for activities}

This stage of the project is concerned with determining what factors drive the costs of executing a specific activity. In most cases these drivers are determined from business understanding, but where the drivers are complex predictive modelling techniques may be used. This information is normally recorded in an ABC modelling tool.

Example cost drivers: execute call (process) call length, time of day, hit rate, skill of operator, product being promoted (Cost drivers).

\section{Collection of cost data}

This stage is concerned with collecting the necessary data to model the costs of activities. This may mean that new measurement systems need to be put in place to allow the input data to be collected. The resulting data provide input into the $\mathrm{ABC}$ modelling process.

Example cost data: call duration 8 min, operator grade 1 , hourly rate £3.00.

\section{ABC model development}

This stage is concerned with running the model and assessing the model's sensitivity to the key cost drivers. In most cases the model(s) would be developed on a sample of data then tested against another sample. This ensures that the data inputs into the original model are not biased in any way.

\section{ABC model validation}

The final model(s) will need to be validated with the business to ensure that what the model surfaces make sense from a business perspective. It may also be necessary to run the model using data from different time periods, to ensure that it is robust and to assess any impact over time.

In most organisations $A B C$ studies tend to be undertaken as pilots in the first place. The results of these pilots often blow away some historical assumptions about the business. This in itself can be a very powerful exercise.

In many cases the pilot itself can produce some very valuable cost data that can be used straight away to refine processes.

\section{$A B C$ roll out}

Having built and validated a model this stage is concerned with putting the $\mathrm{ABC}$ model into production and enhancing the reporting process so that it can be used for management of the business $(\mathrm{AB}$ management). In some cases the $\mathrm{ABC}$ data are integrated with the enterprise balance scorecards and surfaced to the senior management on a regular basis.

\section{CONCLUSION}

$\mathrm{ABC}$ has an important role to play in improving understanding of a number of marketing processes. The following are potential application areas for $\mathrm{ABC}$ in marketing:

— customer profitability analysis

- channel profitability analysis

- channel optimisation

- campaign performance analysis

— response management.

A wider application of $\mathrm{ABC}$ methodologies and associated 
technologies in the marketing functions is likely to be seen. The early adopters will be organisations that are executing complex multi-stage, multi-channel campaigns. It is these organisations that are starting to realise the issues associated with measuring campaign effectiveness in today's marketing environment.

\section{Recommended reading}

The following site provides a wide range of material on $\mathrm{ABC}$ and associated subject areas:

www.bettermanagement.com online resource centre for Activity Based Costing.

The following papers provide good examples of the application of $\mathrm{ABC}$ :
IBM Sales Force Benefits from Automation with ABC, by David L. Carreon. IBM Corporation 2002. www.ibm.com

Willards Foods: Managing Customer Profitability with ABC Information. Keith Phillips, National Brands Ltd. Kevin Dilton-Hill, World Class International 2002

ACB An Introduction by Chris M Pieper, SAS, 2002 www.sas.com.

These can all be found on the bettermanagement.com site.

(C)Shaun Doyle 2002

\section{Reference}

1 Many of these methodologies are covered at www.bettermanagement.com. 